Vol. 37(2), pp. 107-124, Dec. 2018

ISSN 1821-536X (print)

ISSN 2619-8789 (electronic)
Tanzania Journal of Engineering and Technology Copyright (C) 2018 College of Engineering and

Technology, University of Dar es Salaam

Full Length Research Paper

Creative commons licence type CC BY-NC-ND

\title{
Analysis of Drought Using Meteorological and Microwave Remote Sensed Data: A Case of Wami Watershed, Tanzania
}

\author{
Mwajuma Juma and Deogratias M.M. Mulungu* \\ Department of Water Resources Engineering, University of Dar es Salaam, \\ P.O. Box 35131, Dar es Salaam, Tanzania. \\ *Corresponding author: dmulungu@udsm.ac.tz, deorgm@yahoo.co.uk
}

\begin{abstract}
Agricultural sector is important for the economy of Tanzania, but in recent years there is decline in its growth and performance because of persistent droughts. An in-depth study of droughts was conducted on Wami watershed through rainfall and satellite microwave remote sensing data leading for estimates of meteorological droughts and soil moisture based droughts, respectively. Rainfall data during 1973-2008 was used to obtain Drought Severity Index (DSI) and active imaging microwave radar data during 1997-2009 from ESA's SAR missions of ENVISAT and ERS was used to obtain soil moisture anomalies (SMA). Soil map was used to explain discrepancies in droughts from SMA to DSI maps at intervals of time. Seasonality analysis and DSI results showed that the main sub-seasons contributing to rainy season are October through December, January-February and March through May, and drought years were 1984, 1991, 1994, 2004 and 2006. Results showed that the last decade (2000s) had severe droughts that covered $35-39 \%$ of the Wami watershed and could have affected 1128000 people. The soil moisture based drought maps showed the same drought conditions as DSI maps in January, March, May and October. This indicated that in most areas the meteorological droughts can be used to infer to droughts conditions in the soil during the rainy season. The obtained drought events and impacts were confirmed in the field through interviews. However, in July SMA map showed normal and wet conditions whereas it was a dry season for DSI map. This showed that when rainy season ends, the soil still holds some moisture, which can be available for simple crops like vegetables. Therefore, it can be concluded that the SMA was able to provide a better alternative to DSI especially for increased spatial coverage and accuracy of drought monitoring for agricultural production. The SMA enables to map droughts conditions at any point spatially rather than point based DSI maps, which may be prone to rainfall data gaps and spatial interpolation errors. The SMA approach for drought monitoring may be useful to rainfall data scarcity areas of Tanzania and for agricultural droughts risk management.
\end{abstract}

Keywords: Active imaging microwave, Agricultural droughts, Drought indices, Meteorological droughts, Soil moisture based droughts, Wami Basin.

\section{INTRODUCTION}

Meteorological drought is the amount of dryness and duration of the dry period (Moneo and Ana, 2004). It is an interval of time, generally on the order of months or years, during which the actual moisture supply at a given place consistently falls below the climatically appropriate moisture supply. Usually the index that is used to characterize this type of drought only considers rainfall data for the 
reduction in rainfall amounts and doesn't take into account the effects of the lack of water on rivers, water reservoirs, human needs or on agriculture. Relevant to the reduction in agricultural production is the agricultural drought, which links various characteristics of meteorological drought to agricultural impacts, focusing on precipitation shortages, differences between actual and potential evapotranspiration, soil water deficits, reduced ground water of reservoir levels and so forth (NDMC, 2002). Usually the index that is used to characterize this type of drought considers various data such as meteorological, soil moisture and vegetative cover data for the soil water deficits or deficiency for crops growth and development. Accordingly, agricultural drought is typically seen after meteorological drought (when rainfall decreases) but before a hydrological drought (when the water level in rivers, lakes and reservoirs decreases) (Wilhite and Glantz, 1985). It mainly effects food production and farming due to soil water deficits, reduced groundwater or reservoir levels, and so on.

The Wami system encompasses about $43,000 \mathrm{~km}^{2}$ and crosses the political boundaries of five administrative regions of Tanzania; namely Dodoma, Manyara, Morogoro, Tanga and Coast Region. In these regions agriculture is the main socioeconomic activity, which may suffer a significant reduction in yields during droughts thus impacting food security. In accordance with WFP (2013), severe drought hit Tanzania in 2009 and adversely impacted crop production, livestock and power generation. Also, the seasonal forecasts issued by Tanzania Meteorological Agency (TMA), have indicated that some regions of Tanzania including parts of the Wami watershed, will receive below normal rainfall (TMA, 2013), which might have implications on agricultural production and food security as a whole.
Traditional methods of drought detection, monitoring and early warning use pointbased rainfall stations which can have incomplete data and may lack spatial distribution. The rainfall stations are vulnerable to data gaps and spatial coverage limitations since the network of hydro-meteorological gauging stations is declining probably because of socioeconomic and health issues use up the few resources available (Stokstad, 1999; Houghton-Carr and Fry, 2006). Therefore, by using remote sensing (RS) data it can help to gain knowledge on spatial extent and effects without the use of point data. Further, to gain an insight of the effects of meteorological droughts to other types of droughts particularly agricultural droughts, correlation or comparison analysis of meteorological and soil moisture based droughts is recommended. The Synthetic Aperture Radar (SAR) as active imaging microwave remote sensed data from ENVISAT, ERS-1 and ERS-2 Satellite missions of the European Space Agency (ESA) were explored for monitoring drought through soil moisture anomaly (SMA), the index computed for parts of the Wami watershed based on availability of data. Microwave remote sensing has significant advantages for soil moisture retrieval because the sensor is directly sensitive to the soil moisture and it is able to 'see through' clouds (Engman, 1990; Moran et al., 2002). Further, active sensors (e.g. SAR) offer a high spatial resolution for soil moisture monitoring compared with passive sensors (Kong and Dorling, 2008). Microwave can penetrate small clouds (very small particles) with particular frequency range suited for specific applications. Microwave radar images have the potential of quantifying the spatial distribution of volumetric soil moisture due to their ability to penetrate into the soils (over $5 \mathrm{~cm}$ depth from surface) underneath vegetation (Said et al., 2012), depending on the system parameters (e.g. frequency, polarization, etc.), incident wavelength (e.g. C-band), 
environmental conditions (e.g. soil humidity, vegetation density, etc.), and soil characteristics. Active imaging microwave sensors data were the ones that were used to infer soil moisture in the area using a change detection method. Lu et al. (2004) indicated that radar is among the commonly used remotely sensed data for change detection in a local area.

Many change detection techniques for Earth's surface features have been developed for monitoring changes. Lu et al. (2004) presented a comprehensive review of change detection techniques but indicated that research of change detection techniques is still an active topic and new techniques are needed. The most common methods includes image differencing, principal component analysis and postclassification comparison while spectral mixture analysis, artificial neural networks and integration of geographical information system (GIS) and remote sensing data have become important techniques for change detection applications. Generally, the change detection involves the application of multitemporal data sets to quantitatively analyse the temporal effects of the phenomenon (Lu et al., 2004). However, many studies focused on land use and land cover change or vegetation change while very few studies used change detection on time series of radar backscatter observations (Wagner et al., 1999a,b; Zribi et al., 2007; Wagner and Scipal, 2000 in Western Africa) for soil moisture applications. Therefore, there is increasing need to explore the implementation of the change detection techniques for soil moisture applications. This study used image differencing pixel by pixel as well as GIS and RS for change detection applications for soil moisture based droughts using the SAR data. The image differencing is simple and straightforward, easy to interpret the results (Lu et al., 2004). Moreover, using GIS enables integration of other spatial data such as topographic and soil data, and image overlaying in detecting quantitatively the change and attribution. The attribution for soil moisture based droughts was matched with occurrence of meteorological droughts and soil map.

The rainfall data were also analyzed for monitoring meteorological drought through the drought severity index (DSI; Awange et al., 2007) of which it will enable to establish a relationship between meteorological droughts and soil moisture based droughts thereby giving a broad picture of impacts in agricultural production in the watershed areas. The high spatial resolution of SAR data can provide soil moisture anomalies or change detection results at a local level, which can be compared with anomalies derived from point rainfall data. There are no studies that used combined SAR data and meteorological data for estimating drought occurrences. Example of studies in the eastern Africa region that used only meteorological data or in combination with other indices apart from SAR data derived are: Awange et al., 2007; Awange et al., 2008; Mulungu et al., 2008; Mulungu et al., 2011; Nsubuga et al., 2014. Accordingly this study contributes to drought risk management so as to increase society's coping capacity and to develop strategies for mitigating the impacts, leading to greater resilience.

\section{MATERIALS AND METHODS}

\section{The study area}

The Wami River sub-basin is in WamiRuvu Basin, which is among the four drainage basins in Tanzania that drains into the Indian Ocean. The Wami subbasin (Figure 1) lies between Longitudes $35.5^{\circ} 00^{\prime}$ to $39^{\circ} 30^{\prime} \mathrm{E}$ and Latitudes $05^{\circ}$ $00^{\prime}$ to $07^{0} 40^{\prime} \mathrm{S}$. The Wami River originates in the catchment of the Ukaguru, Rubeho, and Nguru mountain ranges, which are all part of the Eastern 
Arc chain of mountains in Kenya and Tanzania. The Wami's river network comprises the main Wami River and its five major tributaries Lukigura, Diwale, Tami, Mvumi/Kisangata and Mkata (WRBO, 2008). Many of the rivers in the Wami watershed are intermittent, ephemeral during the dry season and experience high flows during periods of heavy rainfall. Seasonal flows like rainfall are not uniform across the sub-basin. Mainly the socio-economic activities in the watershed are linked to water supply for domestic use and agricultural production.

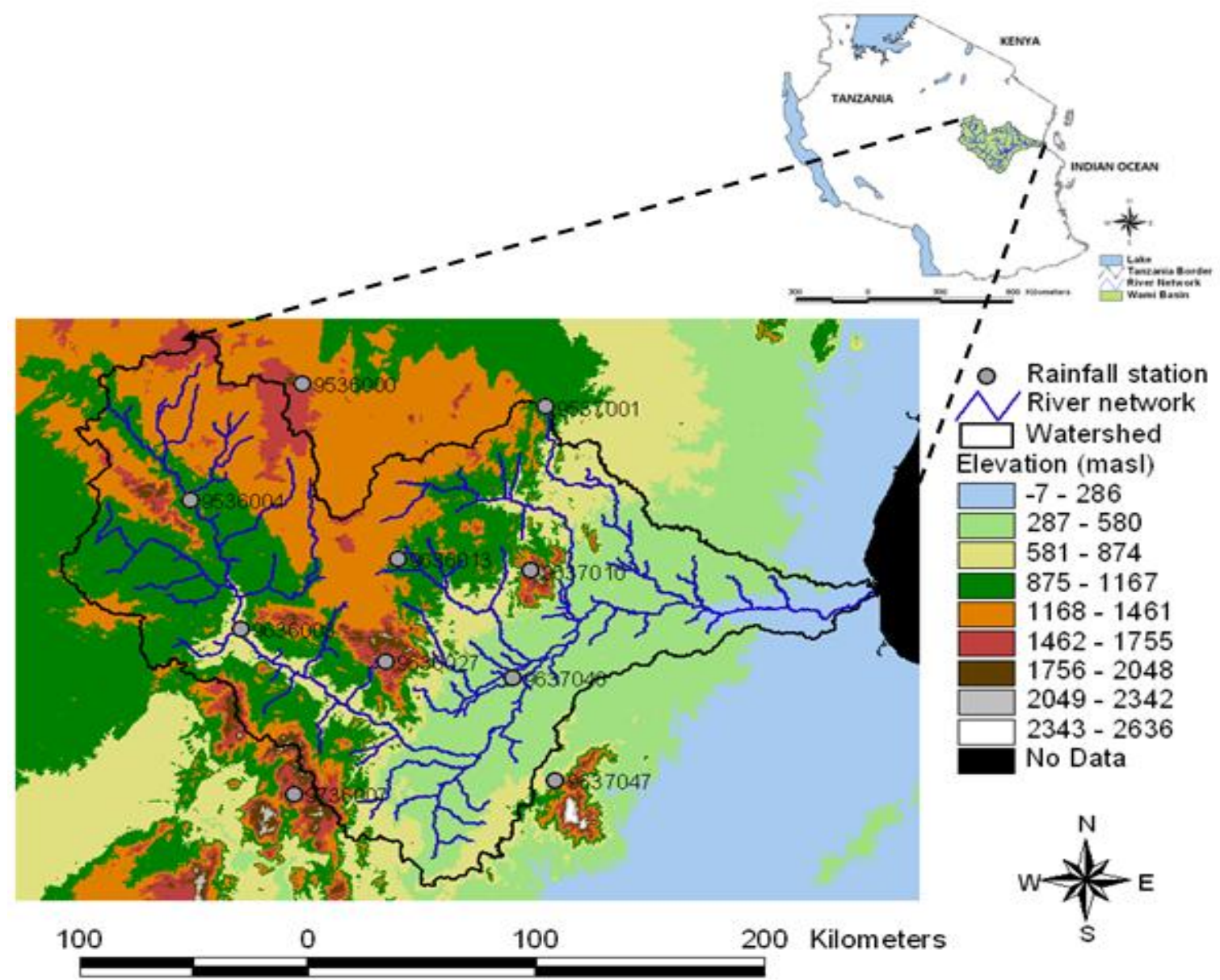

Figure 1: The Wami Watershed with location of selected rainfall stations

Rainfall occurs throughout the year, but variable and unreliable, whereby two rainy seasons are experienced. Heavy and long rains start from March to May while short and small rains occur during October to December, the highest monthly and most reliable rainfall is in April. Average annual rainfall in the area range from 800-1200 $\mathrm{mm}$ in flat land coastal areas of less than $100 \mathrm{~m}$ altitude to $1500 \mathrm{~mm}$ in the mountainous areas of up to 2500 m.a.s.l.

\section{Analysis of Meteorological Droughts}

The rainfall data collected were of variable quality and record length. They were processed so as to improve their quality and put into usable format. Data quality related to specific issues which are length of records, period of record, record continuity, outliers and spatial distribution of stations as criteria. Stations with record of at least 30 years with less than $30 \%$ missing values and those presented even spatial distribution were selected from the inventory. This gave 10 stations during 1973 to 2008 as shown in 
Figure 1. Filling of missing data were done by arithmetic mean, normal ratio and inverse distance methods depending on suitability of the method at different positions of the time series. The suitability of the method was decided by how close estimates and actual values are in a given time series by using descriptive statistics of standard deviation error as criteria. Meteorological droughts were analyzed using monthly values, which were averaged for the number of months in a season to obtain a seasonal mean. The seasons selected for Wami were: JanuaryFebruary (JF), march to May (MAM), June to September (JJAS) and October through December (OND) as they command a share in the rainy season. Annual means were also used by averaging the monthly means for all the 12 months of the year. From the ten rainfall stations, reported in Figure 1, the rainfall seasonal variations indicated that the relatively dry period is between June and September, and sub-seasons of OND, JF and MAM are main contributors to the short and the long rainy seasons having $20 \%, 30 \%$ and $44 \%$, respectively. This implies that if there is deficiency of rainfall in three seasons of OND, JF and MAM it can lead to droughts in the year. In this study, because of significance in agricultural production, these seasons were key for calculating drought events and severities. However, since the SMA was obtained from a day image, the corresponding month was used to compare with the meteorological droughts results on monthly basis when considering the spatial maps.

Meteorological droughts were analyzed for thirty five years during 1973-2008 using the method by Awange et al. (2007). The method was used to determine drought events in a season or year and it is similar to the percent of normal precipitation and deciles for drought detection and monitoring. The normal precipitation $\mathrm{N}$ was calculated by equation (1):
$N=\frac{\sum R_{M}}{n}$

Where $R_{M}$ is either the monthly or seasonal or annual mean and $\mathrm{n}$ is the number of years (i.e. $\geq 30$ in this case 35 years).

The percent of normal $\mathrm{P}_{\mathrm{n}}$ was then given by equation (2):

$$
P_{n}=\left(\frac{R}{n}\right) \times 100 \%
$$

Where $\mathrm{R}$ is the actual rainfall in a month or season or year.

The Drought Severity Index (DSI) was used to establish meteorological droughts events and it was determined by considering as 'dry' all those observations $<25 \%$ (first quartile) of the ranked historical records, while those which are $>75 \%$ (fourth quartile) are considered 'wet'. These thresholds refers to the lower and upper $25 \%$ of data, which are extremes presenting the dry (minimum) and wet (maximum) conditions. Accordingly, droughts are represented by values less than 25\% (Awange et al., 2007; Awange et al., 2008; Nsubuga et al., 2014). The rainfall anomalies were obtained using a standardized quantile in accordance with equation (3).

$$
Z=\left(R_{m}(t)-R_{N}\right) / \sigma
$$

Where $\mathrm{Z}$ is the standardized value of rainfall anomalies giving the DSI, $R_{m}(t)$ is the observed value of rainfall at a particular time $t, R_{N}$ is the $\mathrm{N}$ year (typical 30 years) mean for rainfall in the interval considered and $\sigma$ is the standard deviation. The interval for computation of the mean rainfall can be monthly or seasonal such as OND, JF and MAM.

This gave anomalies that were used for plotting the time series charts. The data were sorted in descending order with values $25 \%$ of the normal and below represented the 'lower threshold'. The 
threshold value was then plotted in the time series, identifying severe and extreme drought as the two main droughts categories (Table 1) with Z (DSI) values below -2. It should be noted that unlike in Awange et al. (2007), this study was able to provide drought thresholds for DSI or anomalies.

Table 1: Wetness and drought categorization thresholds for the anomalies

\begin{tabular}{|l|c|c|}
\hline Physical conditions & \% relative to rainfall mean $\left(\mathbf{P}_{\mathbf{n}}\right)$ & $\begin{array}{c}\text { Estimated Anomaly } \\
\text { Threshold for DSI }\end{array}$ \\
\hline Extremely wet & $>175$ & $>2$ \\
\hline Very wet & 150 to 175 & 1.0 to 2 \\
\hline Near normal wet & 125 to 149.9 & 0.5 to 1 \\
\hline Normal & 75 to 124.9 & -1 to 0.5 \\
\hline Near normal dry & 50 to 74.9 & -1 to -2 \\
\hline Severe drought & 25 to 49.9 & -2 to -4 \\
\hline Extreme drought & $<25$ & $<-4$ \\
\hline
\end{tabular}

\section{Analysis of Soil Moisture-Based Droughts using Imaging Microwave SAR Data}

The active imaging microwave sensors (SAR) data (Table 2) were provided by the European Space Agency (ESA), which limits the amount of data to be provided. The selection of granted ESA products considered data continuity and overlapping in a given segment of the watershed.

Lu et al. (2004) indicated that of the various requirements of pre-processing for change detection, multi-temporal image registration and radiometric and atmospheric corrections, and topographic correction are the most important if the study area is rugged or mountainous. As a result these were included in the preprocessing of SAR data in this study. In addition speckle noise filtering was done in order to remove fluctuation errors in radar measurement so as to easy interpretation of SAR data (Parkes and Clifton, 1999). The image processing software (NEST) of the European Space Agency (ESA) was used to extract the radar backscattering coefficient from the SAR data. Digital image processing was largely concerned with three basics operations: removing antenna pattern, terrain correction), and speckle filtering. This enabled to extract information from the image data. The processing steps followed through a batch processing in NEST software by creating and subsequently run a batch processing functionality. The change detection on time series of $\sigma_{o}$ (radar backscatter) observations (expressed in decibel, $\mathrm{dB}$, for a given pixel) was used to characterize soil moisture droughts in the NEST software using equation (4), which is the TU-Wien model (Wagner and Scipal, 2000) for soil moisture anomaly. 
Table 2: Profile for SAR data products used

\begin{tabular}{|c|c|c|c|c|}
\hline S/N & Mission & Sensor & Product & Acquisition Date \\
\hline 1 & ERS-1 & AMI/SAR/Image & SAR_IMP_1P & $06 / 10 / 1997$ \\
\hline 2 & ERS-2 & AMI/SAR/Image & SAR_IMP_1P & $07 / 10 / 1997$ \\
\hline 3 & ENVISAT & ASAR/IM & ASA_IMP_1P & $14 / 01 / 2003$ \\
\hline 4 & ERS-2 & AMI/SAR/Image & SAR_IMP_1P & $29 / 03 / 2005$ \\
\hline 5 & ERS-2 & AMI/SAR/Image & SAR_IMP_1P & $03 / 05 / 2005$ \\
\hline 6 & ERS-2 & AMI/SAR/Image & SAR_IMP_1P & $14 / 03 / 2006$ \\
\hline 7 & ERS-2 & AMI/SAR/Image & SAR_IMP_1P & $01 / 07 / 2008$ \\
\hline 8 & ERS-2 & AMI/SAR/Image & SAR_IMP_1P & $03 / 03 / 2009$ \\
\hline 9 & ERS-2 & AMI/SAR/Image & SAR_IMP_1P & $16 / 06 / 2009$ \\
\hline 10 & ERS-2 & AMI/SAR/Image & SAR_IMP_1P & $08 / 12 / 2009$ \\
\hline
\end{tabular}

Equation (4) is referred to as standardized anomaly, since it involves subtraction of a data value of a relevant minimum in the numerator to form a transformation. Each transformed value is the difference between the corresponding original data value (extracted radar backscatter observation) and the minimum. The normalization as standardized anomaly is then produced by dividing the anomaly in the numerator by the corresponding range (the difference between maximum and minimum). Wilks (2011) indicated that standardized anomalies can be constructed using resistant measures of location and spread, for example, subtracting the median and dividing by interquartile range (IQR). Accordingly, other statistics such as the range can be used for the normalization, for example, in the vegetation condition index (VCI, Kogan, 1993; Quiring and Ganesh, 2010; Muthumanickam et al., 2011), which uses Normalized Difference Vegetation Index (NDVI) data as input.

The change detection for active microwave observations assumes that the effect of changes in vegetation and surface roughness on the $\sigma_{0}$ observations over time, $\sigma^{o}(t)$ are negligible (Wagner et al., 1999a,b; Zribi et al., 2007; Velde, 2012). As standardized anomaly formulation, equation (4) can be applied to any data regardless of the spatial resolution. A time series approach was used to calculate the minimum and maximum backscatter in equation (4) rather than the absolute minimum and maximum values for the image dataset. This avoided missing of the minimum (dry) and maximum (wet) soil conditions within the small dataset. Accordingly, to find the maximum, $\sigma_{\max }^{o}$ and minimum, $\sigma_{\min }^{o}$ assuming a probability density function as normal or Gaussian distributed with $95 \%$ of a normal distribution captured, equations (5) and (6) were used with the mean, $\sigma_{m n}^{o}$ as well as the standard deviations, $\sigma_{\text {std }}^{o}$ of the overcalling images, calculated using the 'Band Math's' functionality of NEST.

$$
\begin{aligned}
& S M A(t)=\frac{\sigma^{o}(t)-\sigma_{\min }^{o}}{\sigma_{\max }^{o}-\sigma_{\min }^{o}} \\
& \sigma_{\max }^{o}=\sigma_{m n}^{o}+2 \sigma_{s t d}^{o} \cdots . \\
& \sigma_{\min }^{o}=\sigma_{m n}^{o}-2 \sigma_{s t d}^{o} \cdots . . .
\end{aligned}
$$

Wilks (2011) indicated that the use of standardized anomalies is motivated by ideas related to the bell-shaped Gaussian distribution. However, it is not necessary to assume that a batch of data follows any particular distribution in order to reexpress them in terms of standardized anomalies, and transforming non-Gaussian 
data to standardized anomalies will not make their distribution shape be any more Gaussian (Wilks, 2011).

The created $\sigma_{\max }^{o}$ and $\sigma_{\min }^{o}$ bands were used for calculating a SMA map for each of the ten SAR images within the stack using Eq. 2. Five categories of dryness or wetness were used to indicate various degrees severities for SMA: Severe drought, Near normal drought, Normal drought, Very wet, and Extremely wet. Droughts were detected for SMA values less than 0.25 with severe ones near 0 .

\section{Comparison of DSI and pixel SMA and assessment of droughts vulnerable population}

The meteorological drought maps were prepared by spatial analyst tools in ArcGIS using point interpolation of station DSI values. The remote sensing soil moisture maps were readily available as the SMA pixel values. Ten selected points as rainfall stations coordinates (Figure 1) were used and overlaid to the remote sensing map to extract SMA pixel values using BEAM software. To infer differences in soil moisture conditions in relation to soil types at the location of rainfall stations (where DSI values were calculated), a soil map (FAO, 2007; Figure 2) of the watershed was obtained and overlaid with rainfall stations' locations. Table 3 shows the soil texture at the locations of the rainfall stations in the watershed. Also, using purposive sampling, 50 questionnaires were conducted in Kongwa district (Dodoma region) to confirm drought occurrences on the field and compared with DSI and SMA results. The collected data were analyzed using frequency histograms.
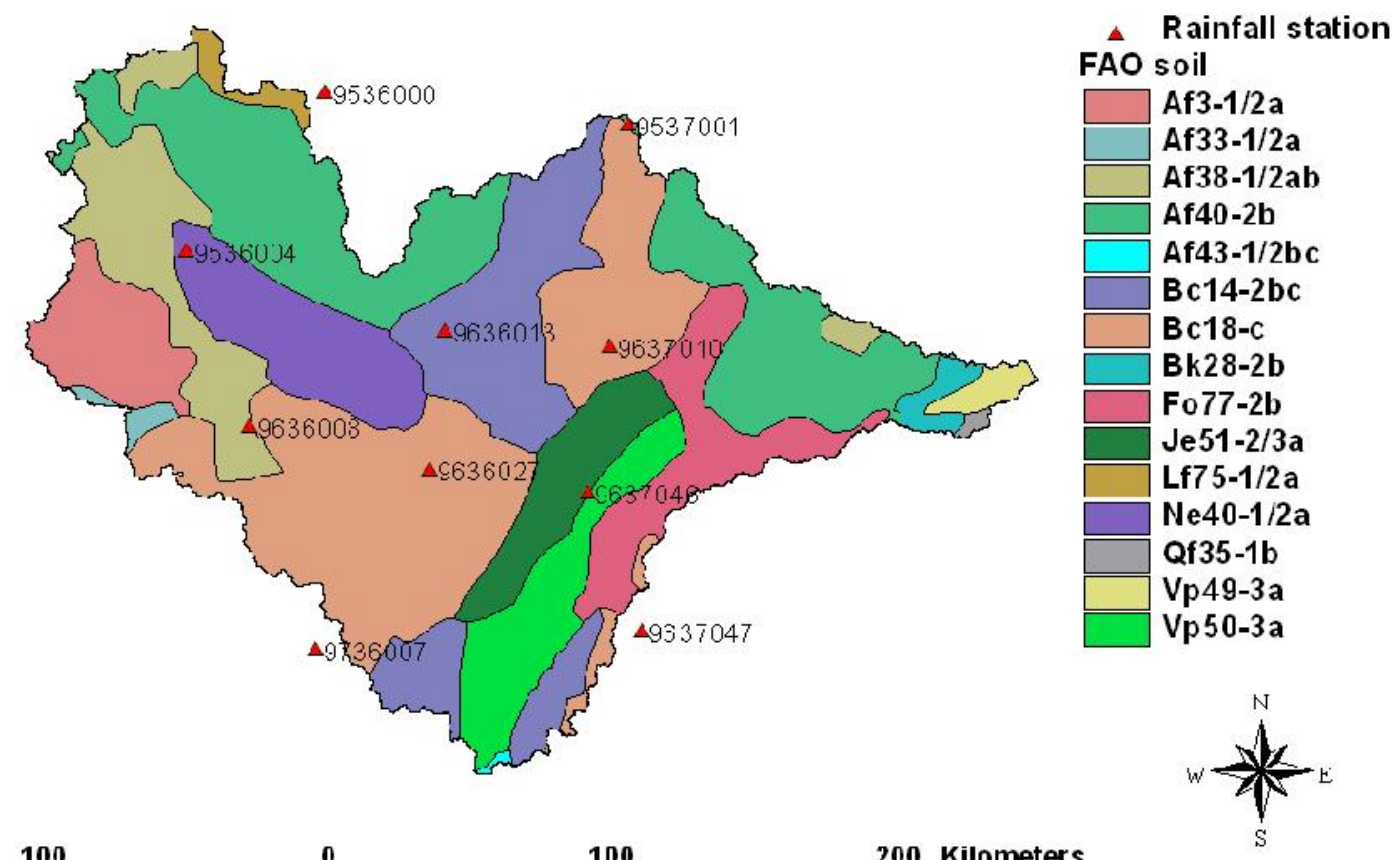

$$
100
$$

Figure 2: Soil map and rainfall stations used for drought analysis in Wami watershed 
Table 3: Soil texture at the rainfall locations in Wami

\begin{tabular}{|l|l|l|l|l|l|}
\hline Station Code & Long. & Lat. & Soil Class & FAO Soil Name & Soil texture \\
\hline 9536000 & 36.57 & -5.28 & Lf75-1/2a & Ferric Luvisols & Loam-sand \\
\hline 9536004 & 36.13 & -5.78 & Ne40-1/2a & Eutric Nitosols & Sand-clay-loam \\
\hline 9636008 & 36.33 & -6.33 & Af38-1/2ab & Ferric Acrisols & Sand-loam \\
\hline 9636013 & 36.95 & -6.03 & Bc14-2bc & Chromic Cambisols & Loam or silt loam \\
\hline 9636027 & 36.90 & -6.47 & Bc18-c & Chromic Cambisols & Loam or silt loam \\
\hline 9637046 & 37.40 & -6.54 & Je51-2/3a & Eutric Fluvisols & Clay-loam \\
\hline 9637047 & 37.57 & -6.98 & Bc18-c & Chromic Cambisols & Loam or silt loam \\
\hline 9736007 & 36.54 & -7.04 & Bc18-c & Chromic Cambisols & Loam or silt loam \\
\hline 9537001 & 37.53 & -5.38 & Af40-2b & Ferric Acrisols & Loam-clay \\
\hline 9637010 & 37.47 & -6.08 & Bc18-c & Chromic Cambisols & Loam or silt loam \\
\hline
\end{tabular}

\section{RESULTS AND DISCUSSION}

\section{Meteorological Droughts}

The values of DSI ranged from less than -4 to greater than 2 with more negative values representing the most serious meteorological droughts while values greater than two indicated wettest conditions. Figure 3 shows an example of meteorological drought analysis plots for selected rainfall stations, which presented severe droughts for the JF and MAM subseasons.

In accordance with Figure 3, for season MAM the severely drought years were 1977, 1984, 2004 and 2006. Out of the ten stations, seven stations had anomaly values exceeding the threshold value of -2 . For seasons JF most of the stations showed the drought years as 1984, 1988, 1991, 2004 and 2006. The condition in the watershed was normal or near normal in other years. These results are similar to other studies in the neighbourhood basin (Mulungu et al., 2011) that used DSI and Normalized Difference Vegetation Index (NDVI), and in the Lake Victoria Basin of Tanzania (Mulungu et al., 2008) that used Standardized Precipitation Index (SPI). The drought events were analyzed for continuity in the sub-seasons of OND, JF and MAM. Results showed varied start and end months giving varied durations of droughts as shown in Table 4.

Table 4: Severe and extreme droughts durations during rainy season

\begin{tabular}{|c|l|l|l|}
\hline $\begin{array}{c}\text { Drought } \\
\text { year }\end{array}$ & Start & End & Duration \\
\hline 1984 & October & February & 5 months \\
\hline 1988 & October & February & 5 months \\
\hline 1991 & October & February & 5 months \\
\hline 1994 & October & February & 5 months \\
\hline 2004 & January & May & 5 months \\
\hline 2006 & January & May & 5 months \\
\hline
\end{tabular}




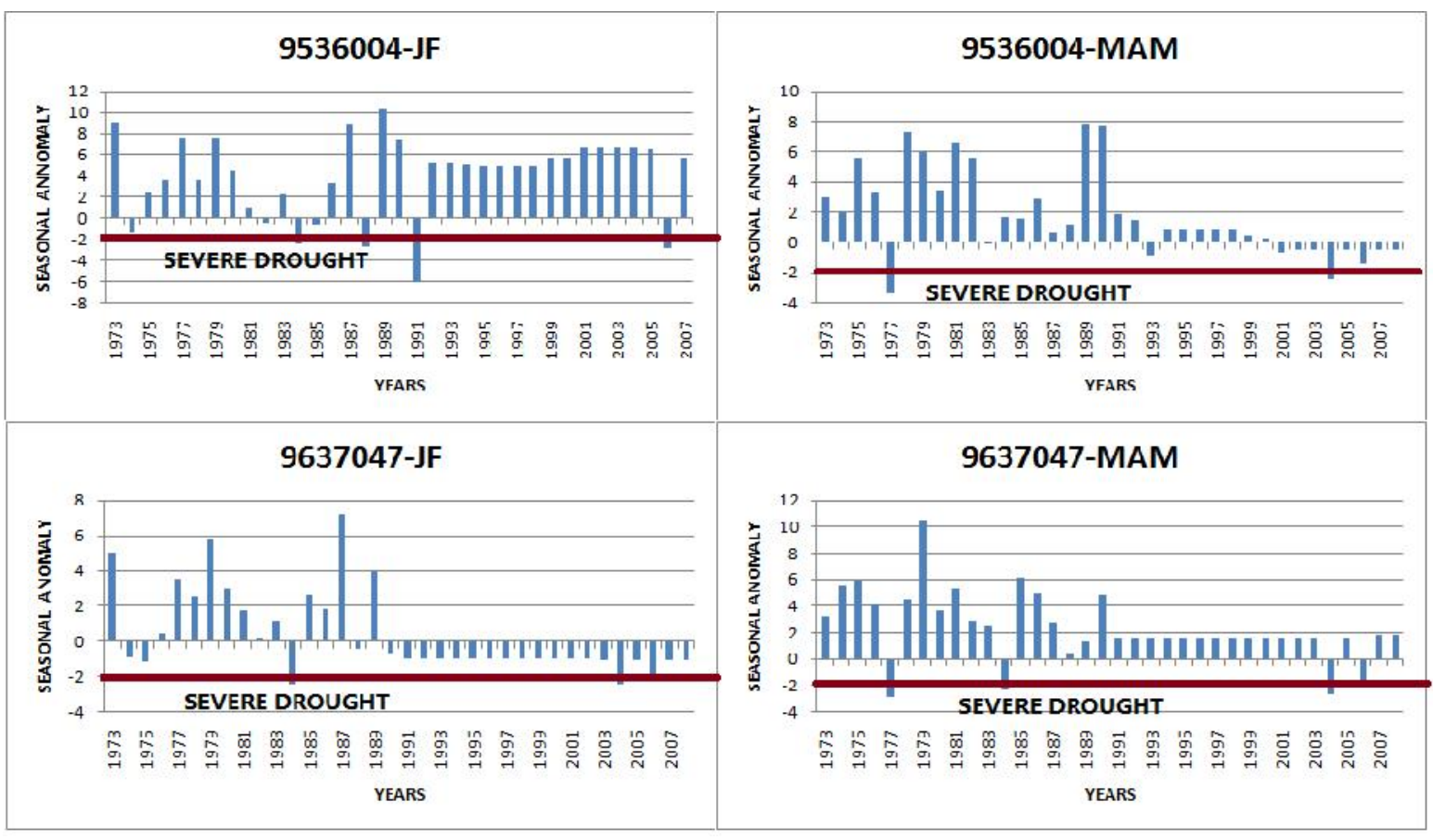

\section{Figure 3: Rainfall anomalies for four selected stations during JF and MAM sub-seasons}

From Table 4, the drought durations persisted for 5 months for the sub-seasons in 1984, 1988, 1991, 1994, 2004 and 2006. However, the droughts in 2004 and 2006 were expected to have major impact on agricultural production as they affected the JF and MAM sub-seasons that contribute a total of $74 \%$ of the rainy season.

The analysis of annual droughts from rainfall anomalies generally indicated that the period from 1973 to 1991 showed mixed spells of wet and normal years with higher and lower anomalies. The period 1991 to 2008 showed a largely normal year dry spell with lower positive anomalies. Generally, it indicated a predominant decrease of rainfall amounts. Therefore, there was no drought year observed for period 1973-2008 that exceeded the threshold anomaly of -2 . This is because annual droughts use all four sub-seasons' (i.e. OND, JF, MAM and JJAS) rainfall, summing them to get annual rainfall. Hence, the dry seasons (JJAS) will merge with higher rainfall seasons like MAM which counteract the dry effect leading to a normal or near normal year on annual time scale.

\section{Soil Moisture Based Droughts}

The values of SMA ranged from values near 0 to near 1 , with values near 0 representing the most serious soil moisture based droughts and values near one indicated wettest conditions. Figure 4 showed examples of the results of soil moisture anomalies for months in different years using the SAR data. Overall, the analysed SAR data represented soil moisture conditions for month of January, March, May and October for various years depending on available data. The colour codes of yellow and red indicated drought conditions. As an example, for January 2003, Figure 4 showed results for anomalies within the basin with SMA values that ranged from severe drought to extremely wet. In March and May 2005, there were near normal to wet conditions distributed all over the basin. 


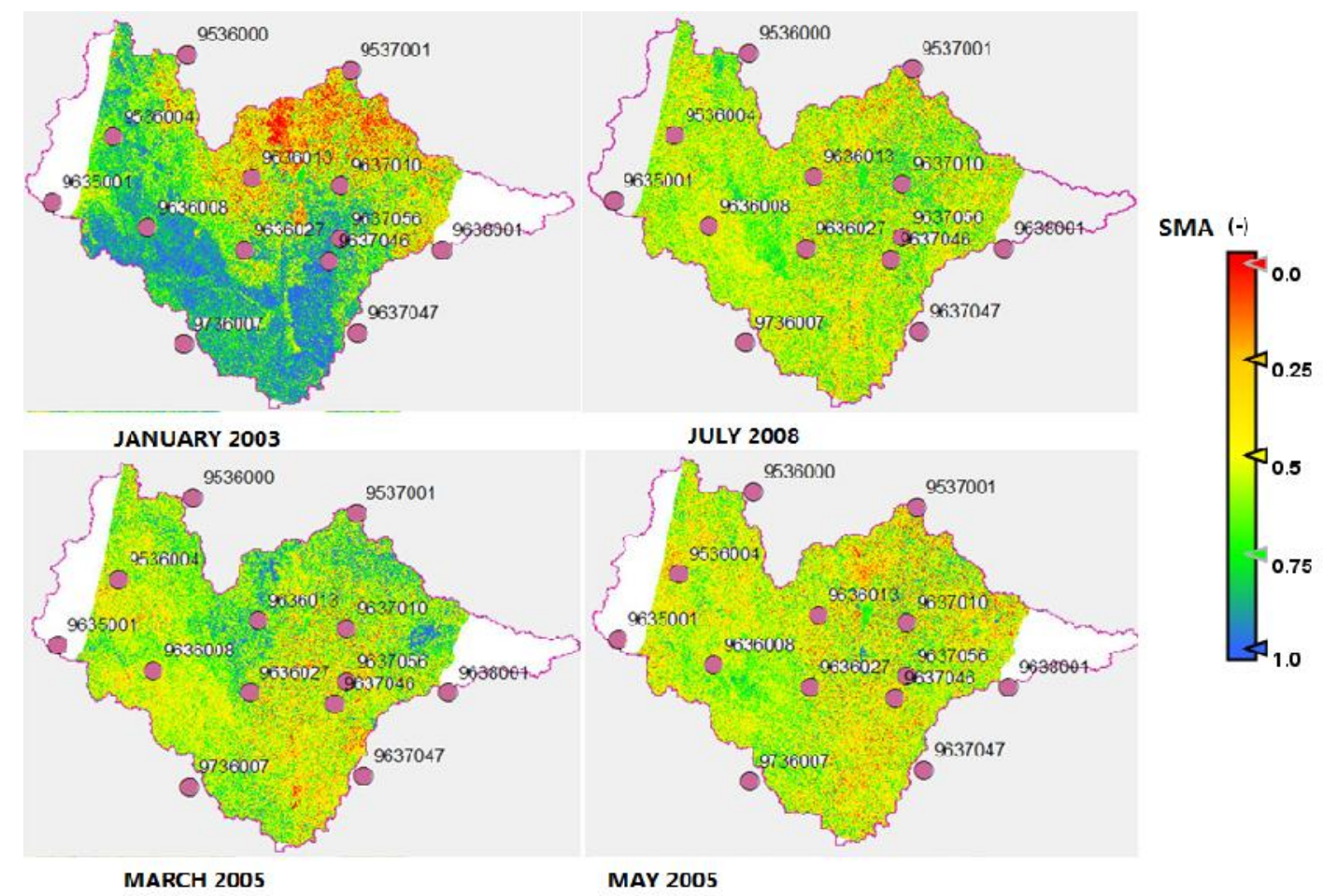

Figure 4: Soil moisture anomaly for different periods during 2003, 2005 and 2008

\section{Comparison of droughts using DSI and SMA}

Figure 5 to 8 illustrates examples of the comparison for DSI and SMA for several months of different years. As indicated, moderate to severe droughts were observed in the months of July and October with soil moisture index of below 0.25 . For DSI, as shown in Figure 5 to 8 , the area was normal from January to May. While for SMA, slightly severe condition was observed in the period of October. Generally, the DSI maps showed broad areas for the levels of physical conditions that are a result of interpolation of point or rainfall station meteorological index whereas the SMA maps showed specific local areas or pixel anomalies for the conditions. For example, in October 1997 (Figure 5), the DSI map showed the whole area was in severe to extreme droughts unlike the SMA map, which showed patches of near normal to extreme wet conditions. In view of that the conditions of local areas from the two indices were compared as explained below.
Table 5 to 8 shows the comparison of point DSI at the rainfall station and extracted SMA pixel values as explained in section 2.3. Generally, the SMA maps in Figure 5 to 8 showed that out of 10 selected points for comparison about seven to ten points had similar interpretation with DSI maps from January, March, May and October. However, for July, SMA map showed that it is normal and wet for some points whereas in DSI map July was a dry season. The SMA for July showed wet and normal for some points but the DSI results showed near normal and severe droughts (Figure 7). This indicates that there is a lag time from meteorological dryness to soil moisture conditions because when the rainfall stops in May, in July the soil still has some moisture and also groundwater is still available hence low soil moisture (drought) cannot be detected at the same time (July). It was difficult to establish the lag time from meteorological droughts to soil moisture based droughts due to the few SAR images available, which can not represent the trend of soil moisture in all twelve months of the same hydrological year. Therefore, it was not possible to see 
the duration of the dry period for microwave images.

In Table 5 to 8 , the discrepancies in soil conditions or drought severities between normal and severe droughts, normal and very wet, and normal and near normal for
SMA and DSI, respectively, may be caused by difference in soil characteristics particularly water-holding capacities. It should be noted that Table 6 and 8 did not indicate the occurrence of a drought for both SMA and DSI.
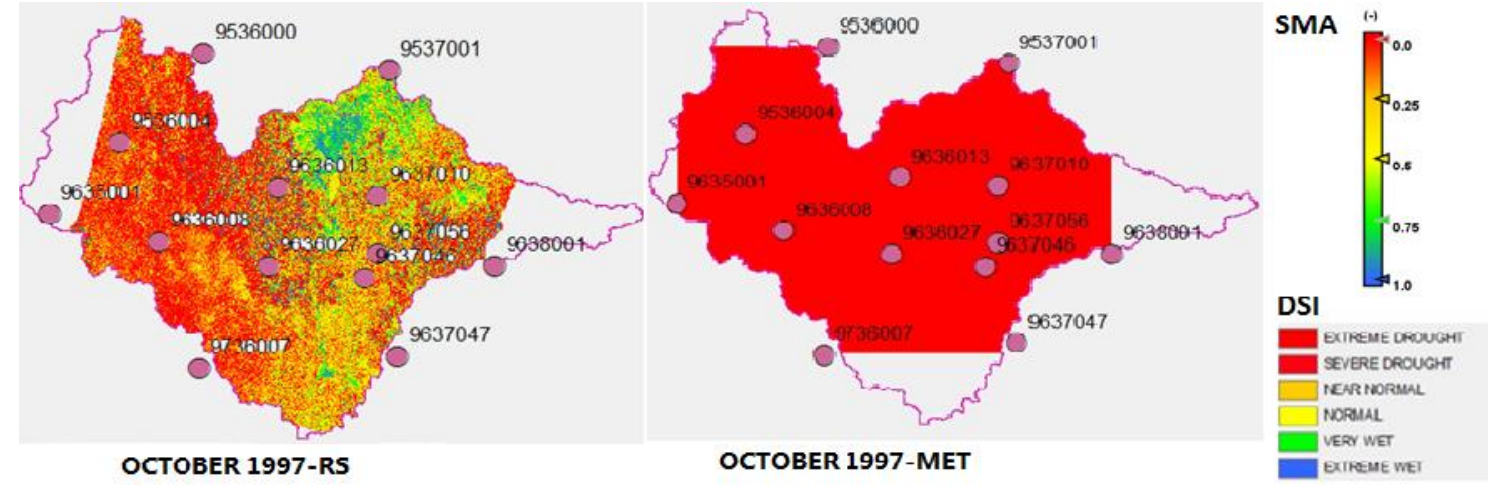

Figure 5: Comparison of remote sensed and meteorological droughts during Oct. 1997

Table 5: Comparison of SMA pixel and DSI values for October 1997

\begin{tabular}{|c|c|c|c|l|c|l|}
\hline $\mathbf{X}$ & Y & Code & SMA & Severity & DSI & Severity \\
\hline 2552.002 & 2439.001 & 9536000 & -0.02784 & Severe drought & -2.75 & Severe drought \\
\hline 1512.017 & 2902.999 & 9536004 & -0.02066 & Severe drought & -2.25 & Severe drought \\
\hline 2072.012 & 4759.000 & 9636008 & 0.07441 & Near normal & -1.53 & Near normal \\
\hline 3751.010 & 3847.000 & 9636013 & -0.03751 & Severe drought & -3.00 & Severe drought \\
\hline 3703.008 & 5271.999 & 9636027 & -0.63130 & Severe drought & -3.31 & Severe drought \\
\hline 4824.016 & 5703.002 & 9637046 & 0.17861 & Near normal & -2.01 & Severe drought \\
\hline 5240.003 & 6679.001 & 9637047 & 0.35439 & Normal & -3.22 & Severe drought \\
\hline 2696.009 & 6343.001 & 9736007 & -0.01811 & Severe drought & -3.44 & Severe drought \\
\hline 5127.013 & 2408.001 & 9537001 & 0.44117 & Normal & -3.65 & Severe drought \\
\hline 5304.007 & 3894.999 & 9637010 & -0.76603 & Severe drought & -2.35 & Severe drought \\
\hline
\end{tabular}

The areas with normal droughts by SMA have soils with high water-holding capacities (Clayey), which are less prone

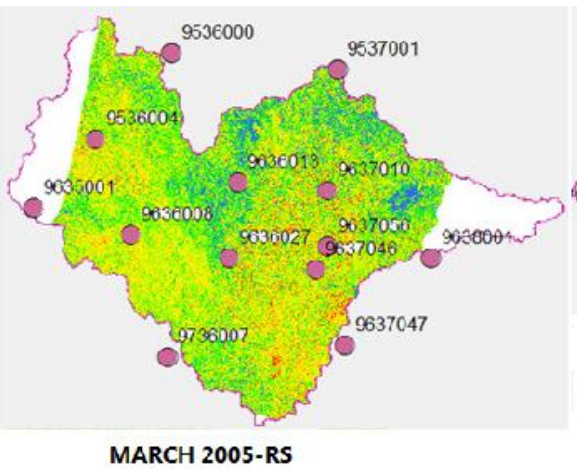

MARCH 2005-RS

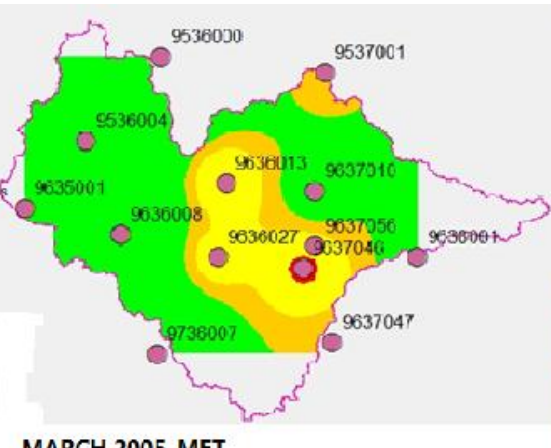

MARCH 2005-MET to soil moisture based droughts hence less prone to agricultural droughts (Table 5).

Figure 6: Comparison of remote sensed and meteorological droughts during Mar. 2005 
Table 6: Comparison of SMA pixel and DSI values for March 2005

\begin{tabular}{|c|c|c|c|l|c|l|}
\hline $\mathbf{X}$ & $\mathbf{Y}$ & Code & SMA & Severity & DSI & Severity \\
\hline 2552.002 & 2439.001 & 9536000 & 0.747843 & Very wet & 1.7 & Very wet \\
\hline 1512.017 & 2902.999 & 9536004 & 0.429847 & Normal & 1.45 & Very wet \\
\hline 2072.012 & 4759.000 & 9636008 & 0.325694 & Normal & 0.43 & Normal \\
\hline 3751.010 & 3847.000 & 9636013 & 0.497414 & Normal & -0.88 & Normal \\
\hline 3703.008 & 5271.999 & 9636027 & 0.421363 & Normal & 0.15 & Normal \\
\hline 4824.016 & 5703.002 & 9637046 & 0.493768 & Normal & 0.07 & Normal \\
\hline 5240.003 & 6679.001 & 9637047 & 0.231458 & Normal & -0.92 & Normal \\
\hline 2696.009 & 6343.001 & 9736007 & 0.746938 & Very wet & 1.51 & Very wet \\
\hline 5127.013 & 2408.001 & 9537001 & 0.479286 & Normal & 0.4 & Normal \\
\hline 5304.007 & 3894.999 & 9637010 & 0.542107 & Normal & 1.93 & Very wet \\
\hline
\end{tabular}

The areas with normal droughts have soils with low water-holding capacities (Sandy or loamy), which are more prone to soil moisture-based droughts hence more prone to agricultural droughts. Also, it is likely that the soil was dry following the transition from short rains to long rains, which occurs in January-February. Therefore, the heavy rainfall in March was used to replenish soil moisture, which was at low level hence normal soil moisture conditions in the soil (Table 6).

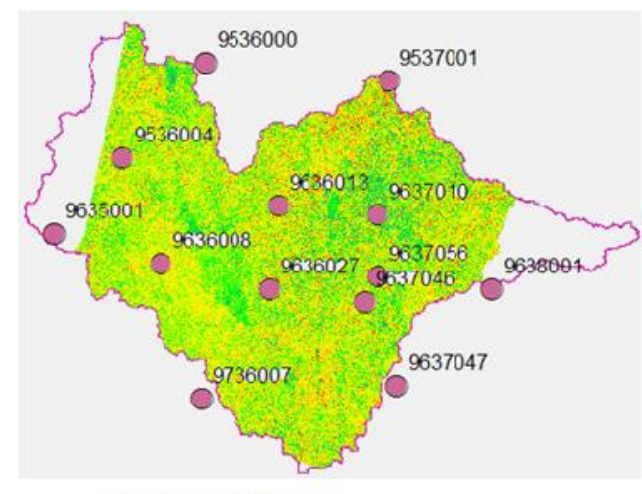

JULY 2008-RS
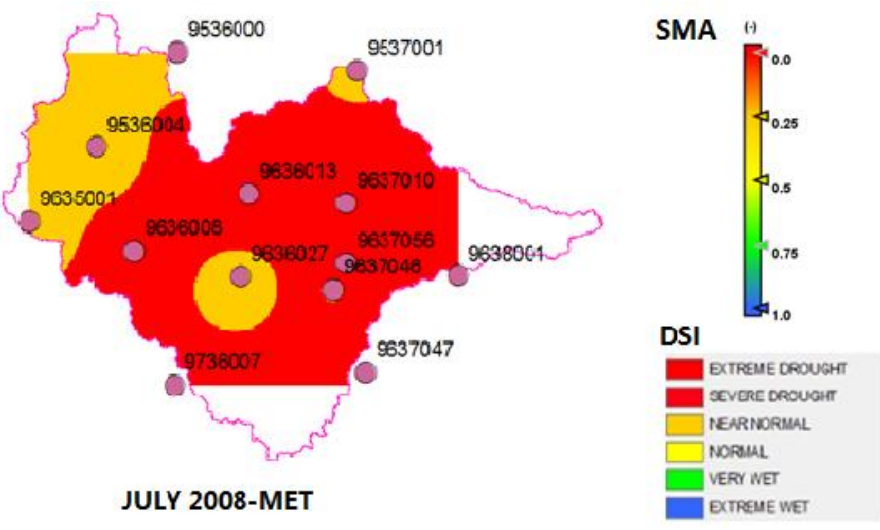

Figure 7: Comparison of remote sensed and meteorological droughts during July 2008 
Table 7: Comparison of SMA pixel and DSI values for July 2008

\begin{tabular}{|c|c|c|c|c|c|c|}
\hline $\mathbf{X}$ & Y & Code & SMA & Severity & DSI & Severity \\
\hline 2552.002 & 2439.001 & 9536000 & 0.724975 & Very wet & -1.29 & Near normal \\
\hline 1512.017 & 2902.999 & 9536004 & 0.747993 & Very wet & -1.58 & Near normal \\
\hline 2072.012 & 4759.000 & 9636008 & 0.467775 & Normal & -5.25 & Severe drought \\
\hline 3751.010 & 3847.000 & 9636013 & 0.336646 & Normal & -1.03 & Severe drought \\
\hline 3703.008 & 5271.999 & 9636027 & 0.453433 & Normal & -1.93 & Near normal \\
\hline 4824.016 & 5703.002 & 9637046 & 0.714659 & Very wet & -2.47 & Severe drought \\
\hline 5240.003 & 6679.001 & 9637047 & 0.873440 & Very wet & -1.52 & Severe drought \\
\hline 2696.009 & 6343.001 & 9736007 & 0.285112 & Normal & -2.11 & Severe drought \\
\hline 5127.013 & 2408.001 & 9537001 & 0.134767 & Near normal & -1.52 & Near normal \\
\hline 5304.007 & 3894.999 & 9637010 & 0.198065 & Near normal & -2.27 & Severe drought \\
\hline
\end{tabular}

As July is a dry season, the discrepancy in severity levels may be caused by differences in moisture conditions in the soil and the atmosphere as indicated earlier. Peculiar is the discrepancy in drought severities between very wet and severe droughts for SMA and DSI, which may be caused by soils with high waterholding capacities (Clayey), which are less prone to soil moisture based droughts hence less prone to agricultural droughts (Table 7).

Table 8: Comparison of SMA pixel and DSI values for May 2005

\begin{tabular}{|c|c|c|c|l|r|l|}
\hline $\mathbf{X}$ & $\mathbf{Y}$ & Code & SMA & Severity & DSI & Severity \\
\hline 2552.002 & 2439.001 & 9536000 & 0.466844 & Normal & -0.99 & Normal \\
\hline 1512.017 & 2902.999 & 9536004 & 0.363546 & Normal & 0.33 & Normal \\
\hline 2072.012 & 4759.000 & 9636008 & 0.483460 & Normal & 0.60 & Near normal \\
\hline 3751.010 & 3847.000 & 9636013 & 0.498425 & Normal & 0.48 & Normal \\
\hline 3703.008 & 5271.999 & 9636027 & 0.261363 & Normal & 0.15 & Normal \\
\hline 4824.016 & 5703.002 & 9637046 & 0.287885 & Normal & 2.07 & Normal \\
\hline 5240.003 & 6679.001 & 9637047 & 0.331211 & Normal & 0.35 & Normal \\
\hline 2696.009 & 6343.001 & 9736007 & 0.488944 & Normal & 0.54 & Near normal \\
\hline 5127.013 & 2408.001 & 9537001 & 0.328748 & Normal & 0.28 & Normal \\
\hline 5304.007 & 3894.999 & 9637010 & 0.484017 & Normal & 0.77 & Normal \\
\hline
\end{tabular}
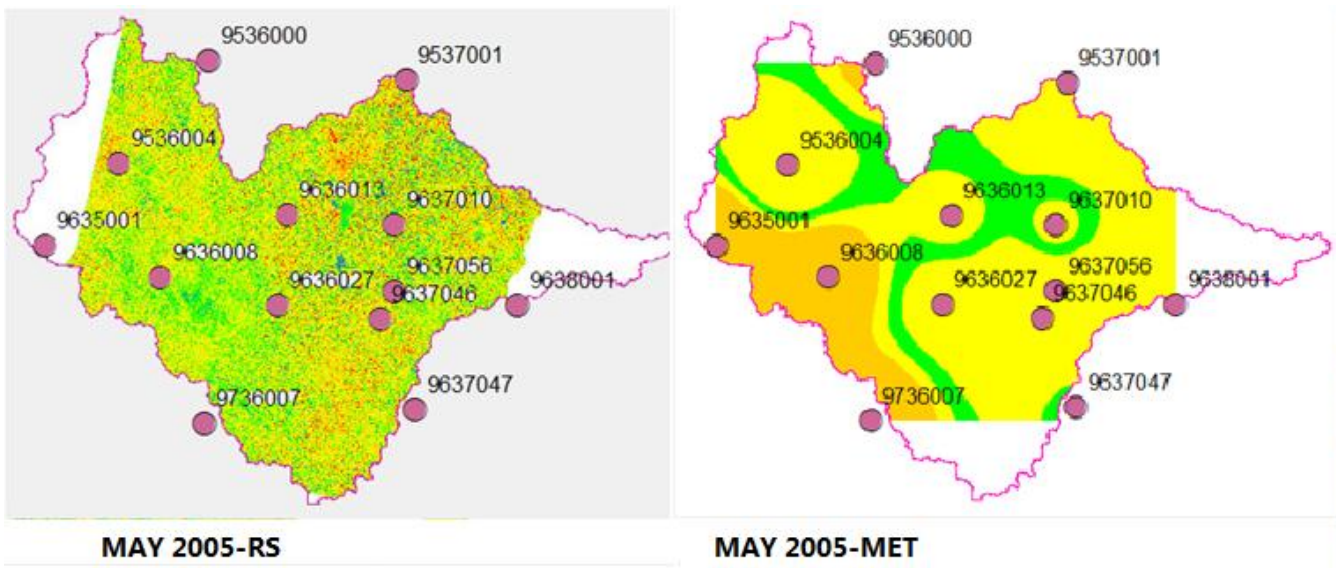

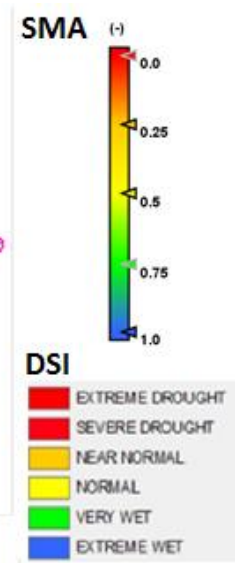

Figure 8: Comparison of remote sensed and meteorological drought during May 2005 
The difference in soil characteristics is not significant when soil conditions are normal and near normal for SMA and DSI, respectively (Table 8). This indicates that towards the end of rainy season there were relatively low moisture conditions in the soil and atmosphere.

\section{Drought occurrence from questionnaire survey and literature search}

Generally the results obtained through questionnaires mostly correlated with drought occurrences from DSI and SMA analyses. Figure 9 shows drought occurrences and their severities as reported from the interviews. The interview results indicated occurrences of droughts in the study area, which had effects on water supply and irrigation schemes. Consequently, the drought severities coincided with their effects on water supply schemes, resulting into conflicts between river water users due to water abstractions for irrigated schemes by farmers, which render little or no water to users downstream. Results showed that the period 1980-1985 recorded highest in terms of severity and impacts followed by the period 2006-2010. This field-based results coincides with DSI and SMA analysis in this study (Table 9).

Apart from questionnaire results, there is also supported evidence indicating that the droughts were very severe in some parts of the catchment area including Kongwa (nearer rainfall stations are: 9636008 with droughts during MAM in 2004 and 9636027 with droughts during JF in 2004, which suffered a food crisis according to the report provided by Red Cross International 2006. The report noted that poor rainfall had significantly reduced pasture and water availability, resulting in massive emaciation including deaths of livestock, notably cattle in the pastoral and agro-pastoral zones. It was reported that on 14 February 2005, the government officially requested international assistance and asked for 100,000 metric tons of food. The UN's World Food Programme (WFP) coordinated international food donations in year 2005, which was extended up to year 2006. This food was distributed to 26 affected regions in Tanzania, including areas in Wami catchment in Manyara and Dodoma regions. This also tallies with the DSI and SMA results as 2004 and 2006 were drought years, which affected the long rains in the main growing season (Table 4).

The affected area spatially comprises the percentage of the total area affected as shown in Table 9 for DSI. The total population of the Wami watershed according to the 2012 census was estimated to be around 1,410,000 people from Kongwa, Mpwapwa, Kondoa, Kiteto, Kilindi, Handeni, Bagamoyo, Kilosa and Mvomero districts area proportions in the Wami basin area. Due to the fact that around $80 \%$ of Tanzanians live in rural area (Shemsanga et al., 2010), it was assumed that they engage in agricultural activities and therefore it was estimated that around 1,128,000 people were at risk of being affected by droughts in the watershed.

Table 9: Severe drought affected area by percentage using DSI

\begin{tabular}{|c|c|c|}
\hline $\begin{array}{c}\text { Drought } \\
\text { year }\end{array}$ & $\begin{array}{c}\text { Area } \\
\text { percentage }\end{array}$ & $\begin{array}{c}\text { Drought } \\
\text { Severity }\end{array}$ \\
\hline 1984 & $45 \%$ & Severe \\
\hline 1988 & $27 \%$ & Moderate \\
\hline 1991 & $36 \%$ & Severe \\
\hline 1994 & $29 \%$ & Moderate \\
\hline 2004 & $39 \%$ & Severe \\
\hline 2006 & $35 \%$ & Severe \\
\hline
\end{tabular}




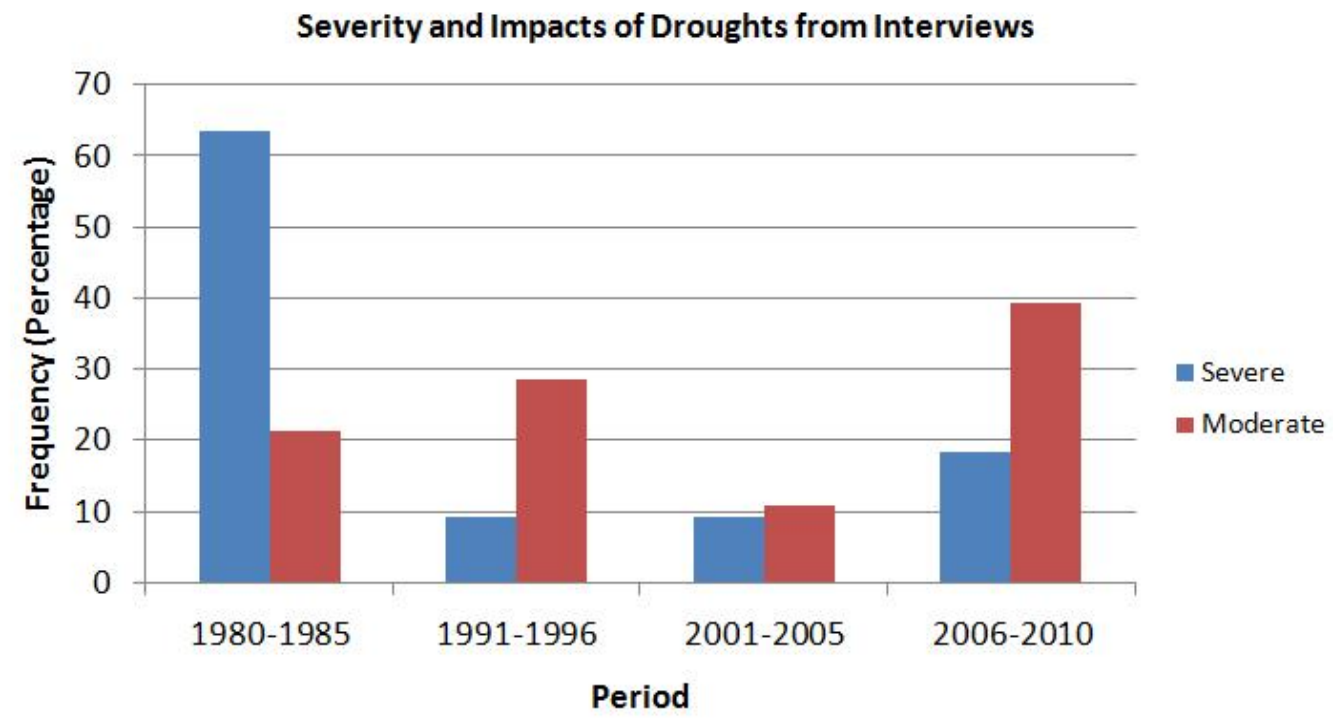

Figure 9: Drought occurrences, severity and their impacts from field interviews

\section{CONCLUSIONS AND RECOMMENDATIONS}

Based on the findings of this research work, it was concluded that the soil moisture based droughts were well correlated with meteorological droughts presented as DSI values during the months of January, March, May and October. These correlations indicated that the SAR data through the SMA performed similarly with DSI in monitoring droughts. This indicated that the meteorological droughts can be used to infer to droughts conditions in the soil during the rainy season. However, for July there was no correlation on almost all points selected which indicated that there was a lag between the SMA and DSI values in this month because when rainfall stops at the end of season MAM, some moisture still remains in the soil and hence drought cannot be detected. Past studies in Tanzania showed that droughts occurred during 1984, 1988, 1991, 1994, 2004, which is similar to the results of seasonal analysis of droughts in the Wami basin. However, contrasting extreme and severe for SMA, posed a limitation for SMA index, which can be considered in a future study.
Further, the study showed that SAR data through the SMA can be used as a good indicator to monitor droughts spatially in the catchment when rainfall data are not available particularly during January, March, May and October. The SMA gives drought conditions at any point spatially rather than interpolating DSI values from point rainfall data. Since SMA responds well to the soil water availability, it can be a good indicator of crop stress and thus agricultural droughts conditions. The SMA maps can be used in future studies to develop agricultural droughts risk management and plans in the watershed. Due to limitation provided by ESA on acquiring the SAR data it was not feasible to get the nature of soil moisture based droughts for the full years, which could help in determining lag times between soil moisture based droughts and meteorological droughts. Future research can be done by acquiring data for all twelve months in a year per overlying segment in order to establish the lag times. Moreover, a land use or cover map of the watershed can be considered in the analysis in order to clarify more the SMA results particularly in forested areas where the soil moisture sensed by SAR data could probably come from vegetation unlike the soil. 


\section{ACKNOWLEDGEMENTS}

Sincere gratitude is extended to European Space Agency (ESA) for providing Synthetic Aperture Radar (SAR) data which were used for analysis of soil moisture based droughts. The authors are also grateful to Tanzania Integrated Water, Sanitation and Hygiene (iWASH) program of USAID/Tanzania for providing financial support to the first author for Masters degree research work upon which this paper is based.

\section{REFERENCES}

Awange J.L., Aluoch J., Ogallo L.A., Omulo M. and Omondi P. (2007). Frequency and severity of drought in the Lake Victoria region (Kenya) and its effects on food security. Climate Research, 33: 135-142.

Awange J.L., Ogalo L., Bae K., Were P., Omondi P., Omute P. and Omullo M. (2008). Falling Lake Victoria water levels: Is climate a contributing factor? Climate Change, 89(3-4): 281297.

Eastman J.R. (2001). Guide to GIS and Image Processing, IDRISI Production, USA.

Engman E.T. (1990). Progress in microwave remote sensing of soil moisture. Canadian Journal of Remote Sensing, 16: 6-14.

FAO (2007). Digital Soil Map of the World, 1:5,000,000 scale. United Nations Food and Agriculture Organization (FAO), Rome, Italy.

Houghton-Carr H. and Fry M. (2006). The decline of hydrological data collection for development of integrated water resources management tools in Southern Africa. In: S. Demuth et al. (eds), International Association of Hydrological Sciences (IAHS), Fifth FRIEND world conference, Havana, Cuba.

Kogan F. (1993). Development of global drought-watch system using
NOAA/AVHRR data. Advances in Space Research, 13(5): 219-222.

Kong X. and Dorling S.R. (2008). Nearsurface soil moisture retrieval from ASAR Wide Swath imagery using a Principal Component Analysis. International Journal of Remote Sensing, 29(10): 2925-2942.

Lu D., Mausel P., Brondízio E. and Moran, E. (2004). Change detection techniques. International Journal of Remote Sensing, 25(12): 2365-2401.

Moran M.S., Hymer D.C., QI J. and Kerr Y. (2002). Comparison of ERS-2 SAR and Landsat TM imagery for monitoring agricultural crop and soil conditions. Remote Sensing of Environment, 79: 243-252.

Mulungu D.M.M., Mtalo F.W., Mkhandi S.H., Fohrer N. and Schamalz B. (2008). Characterisation and monitoring of agricultural droughts in Simiyu River catchment, Tanzania, 9th Waternet/ WARFSA/ GWP-SA Symposium, 29-31 October, Johannesburg, South Africa.

Mulungu D.M.M., Sseguya F. and Mashingia F. (2011). Relating Maize yield with vegetative index and meteorological drought in Ruvu basin, Tanzania, 12th Waternet/ WARFSA/ GWP-SA Symposium, 26-28 October 2011, Maputo, Mozambique.

Muthumanickam D., Kannan P., Kumaraperumal R., Natarajan S., Sivasamy R. and Poongodi C. (2011). Drought assessment and monitoring through Remote sensing and GIS in western tracts of Tamil Nadu, India. International Journal of Remote Sensing, $\quad 32(18)$ : 5157-5176. https://doi.org/10.1080/01431161.201 0.494642 .

NDMC (National Drought Mitigation Center) (2002). Drought basics, University of Nebraska-Lincoln, USA. Available online at http://drought.unl.edu/Education/Drou ghtBasics.aspx. Retrieved on $30^{\text {th }}$ December 2018. 
Nsubuga F.W.N., Botai O.J., Olwoch J.M., deW Rautenbach C.J., Bevis Y. and Adetunji A.O. (2014). The nature of rainfall in the main drainage subbasins of Uganda. Hydrological Sciences Journal, 59(1-2): 278-299.

Parkes S.M. and Clifton H.L. (1999). The compression of raw SAR and SAR image data. International Journal of Remote Sensing, 20(18): 3563-3581.

Quiring S.M. and Ganesh S. (2010). Evaluating the utility of the vegetation condition index (VCI) for monitoring meteorological drought in Texas. Agricultural and Forest Meteorology, 150(3): 330-339.

Valimba P. (2007). Environmental Flow Assessment Study (EFA), Wami River Sub-basin, Tanzania: The Wami Hydrology. Volume 1 - General Description. Wami-Ruvu Basin Water Office. 42p.

van der Velde R. (2012). Synthetic Aperture Radar data processing with the Next ESA SAR Toolbox (NEST) and Flood and Soil Moisture mapping applications. Unpublished manuscript. University of Twenty, ITC, The Netherlands.

Said S., Kothyari U.C. and Arora M.K. (2012). Vegetation effects on soil moisture estimation from ERS-2 SAR images. Hydrological Sciences, 57(3): 517-534.

Shemsanga C., Omambia A.N. and Gu Y. (2010). The Cost of Climate Change in Tanzania: Impacts and Adaptations. Journal of American Science, 6(3): 182-196.

Stokstad E. (1999). Hydrology-scarcity of rain, stream gages threatens forecasts. Science, 285(5431): 1199-1200.

TMA (Tanzania Meteorological Agency) (2013). Seasonal Forecasts. Tanzania rainfall outlook for October to December. Press release accessed on 10th October 2013 at www.tma.go.tz; www.meteo.go.tz.

Wagner W., Lemoine G. and Rott $\mathrm{H}$. (1999a). A method for estimating soil moisture from ERS Scatterometer and soil data. Remote Sensing of Environment, 70: 191-207.

Wagner W., Noll J., Borgeaud M. and Rott H. (1999b). Monitoring soil moisture over the Canadian Prairies with the ERS scatterometer. IEEE Transactions on Geoscience and Remote Sensing, 37: 206-216.

Wagner W. and Scipal K. (2000). Largescale soil moisture mapping in Western Africa using the ERS scatterometer. IEEE Transactions of GeoSciences in Remote Sensing.

Wilhite D.A. and Glantz M.H. (1985). understanding the Drought Phenomenon: The role of definitions. Water International, 10(3): 111-120.

Wilks D.S. (2011). Statistical Methods in the Atmospheric Sciences. Third edition, International geophysics series, Volume 100, USA.

WFP (World Food Program) (2013). Comprehensive Food Security and Vulnerability Analysis (CFSVA) Tanzania 2012. United Nations World Food Programme, Rome, Italy, 74p.

WRBO (2008). Business plan. Wami Ruvu Basin Water Office, Morogoro.

Zribi M., Saux-picart S., Andre C., Descroix L., Ottle C. and Kallel A. (2007). Soil moisture mapping based on ASAR/ENVISAT radar data over a Sahelian region. International Journal of Remote Sensing, 28(16): 35473565 . 